\title{
Peer Assignment Review Process for Collaborative E-learning: Is the Student Learning Process Changing?
}

\author{
Evelyn Kigozi Kahiigi \\ Department of Computer and Systems \\ Sciences \\ Stockholm University, Sweden
}

\author{
Henrik Hansson \\ Department of Computer and Systems Sciences \\ Stockholm University, Sweden
}

\author{
Mikko Vesisenaho \\ University of Jyväskylä, \\ Finland
}

\author{
F.F Tusubira \\ Knowledge Consulting Ltd \\ Kampala, Uganda
}

\author{
Mats Danielson \\ Department of Computer and Systems Sciences \\ Stockholm University, Sweden
}

\begin{abstract}
In recent years collaborative e-learning has been emphasized as a learning method that has facilitated knowledge construction and supported student learning. However some universities especially in developing country contexts are struggling to attain minimal educational benefits from its adoption and use. This paper investigates the application of a peer assignment review process for collaborative e-learning to third year undergraduate students. The study was aimed at evaluating the effect of the peer assignment review process on the student learning process. Data was collected using a survey questionnaire and analyzed using SPSS Version 16.0. While the student reported positive impact of the peer assignment review process in terms of facilitating students to put more effort and improve their work; quick feedback on their assignments; effective sharing and development of knowledge and information and the need of computer competence to manipulate the peer assignment review system, analysis of the quantitative data indicated that the process had limited effect on the learning process. This is attributed to lack of review skills, absence of lecturer scaffolding, low ICT literacy levels and change management.
\end{abstract}

Keywords-Peer Review; Collaborative E-learning; Learning Process; Students; University; Uganda; Developing Country.

\section{INTRODUCTION}

The use of collaborative e-learning has been proposed to support learning by motivating students to share ideas, make critical judgment, reflect on their work as a result enforcing knowledge development and learning [1]. As a result the collaborative e-learning process has been widely recognized as a learning tool that supports students' performance [2]. Indeed, several learning theories have been used to explain the collaborative e-learning concept. Collaborative e-learning can be explained basing on social constructivism that relates to individuals constructing their knowledge through the process of negotiating meanings with others within the learning community [3]. With the social constructivism perspective the pedagogical approach is shifted from learning that focuses on delivery of content knowledge to collaborative learning aimed to facilitate acquisition of higher learning skills [3]. From a constructivist perspective of learning associated with Vygotsky's [4] zone of proximal development, the learner's level of understanding and cognitive development are attained through social interaction and collaboration. This implies that collaborative e-learning can allow learners develop an understanding and master various aspects in a course better than when working alone. Piaget's [5] work views collaborative e-learning as an active process that engages students in learning by giving them some ownership in their instruction. Piaget affirms that having access to peers work can provide new perspectives that challenge the student's understanding. Feedback received may cause cognitive dissonance to encourage students to modify his or her concepts resulting into new learning. By working together, students are able to accomplish and learn more than they could individually [6]. Students are given an opportunity to judge and compare their work with peers' work resulting in some level of understanding and knowledge creation. Indeed Topping et al.[7] view feedback as an integral part of a learning process through which students construct knowledge and develop their learning.

The collaborative e-learning concept using peer reviews has been investigated in numerous studies and learning scenarios that have facilitated knowledge construction and supported student learning. Sahin [8] validated peer evaluation in higher education and established a similarity with lecturer evaluation. Richardson et al.[9] evaluated the effectiveness of a peer feedback strategy in asynchronous online discussion. Students perceived the peer feedback as having impacted on their learning at a higher cognitive level, such as critical thinking skills. Lan et al. [10] on the other hand developed a conceptual framework for providing intelligent support through agent negotiation and fuzzy constraints to enhance the effectiveness of peer assessment. Student's performance significantly improved, the negotiation mechanism improved the assessment accuracy and thus students accepted the assessment results and reflected upon their work. Although benefits derived from peer 
review have been acknowledged and demonstrated, studies have also revealed challenges. Challenges reported in Kahiigi et al. [11] and Sahin [8] include students lack of skills to engage in meaningful reviews that are informative; validity and reliability of grades given by students resulting from lack of expertise and potential bias; negative attitude towards peer reviews; students being uncomfortable in carrying out assessments with a notion that it is the teachers' responsibility to assess and award grades, thus considering it an additional burden. These challenges have resulted into high levels of subjectivity thus limiting the adoption and use the peer review concept.

In this regard, the study presented in this paper aims to evaluate the effectiveness of the peer assignment review process for collaborative e-learning in an undergraduate Database Management Systems course. Specifically the study analyses the impact of the peer assignment review process and the change in the student learning process. The research questions discussed at this stage are: Does collaborative elearning support student learning? And if so how has the learning process changed? In this paper collaborative elearning is defined as a learning method that facilitates knowledge construction, negotiating meanings and solving problems to achieve a learning goal through mutual interaction between students using Information and communication technology (ICT).

\section{Methodology}

\section{A. Case Description}

The present study was carried out at Makerere University, College of Computing and Information Sciences between October and December 2011 with 998 third year undergraduate students enrolled in a Database Management Systems (DBMS) course. The DBMS course was a cross cutting course for students registered for Bachelors of Science in Software Engineering (BSE), Bachelors of Science in Computer Science (CSC), Bachelors of Information Technology (BIT) and Bachelors of Information Systems (BIS). This course was unique as it was taken by students from various disciplines and had a large student population. This DBMS course aimed to provide students with a strong foundation in systematic approaches to design and implementing of database applications and to provide a practical experience and knowledge in developing database driven applications in real world scenarios.

The DBMS course selection was based on: a) students using e-learning in their learning activities; and b) and the will of the lecturer to participate and drive students' involvement in the study. Noteworthy is that while all students registered to the different courses were part of the studies; involvement in the survey was voluntary.

\section{B. Case Study Procedure}

The DBMS course was traditionally taught by three lecturers following the same course outline with lectures held in a classroom setting on campus. The peer assignment review process was embedded within the course and marks earned on the assignment formed part of the final course evaluation. As a result student participation in the peer assignment review process was mandatory and participation in the study was voluntary. While the course had other course activities within an online and traditional learning environment, this study focused on the peer assignment review process that was introduced in the student's first course assignment.

Students followed the peer assignment review process stages these were: familiarization, assignment, review and feedback [11].During the familiarization stage students were introduced to the peer assignment review process and had a demonstration of the peer review application integrated into the Makerere University E-learning Environment (MUELE), the learning management system based on Moodle. A question and answer session was scheduled at the end of the demonstration to facilitate a deeper understanding and elaboration of peer assignment review process. The familiarization stage aimed to equip students with peer review skills. At the assignment stage, students were then given the assignment which was supposed to be submitted online using MUELE. After the submission deadline, which was scheduled to take place during the classroom sessions, the lecturers presented and discussed the marking criteria with the students. This exposed the students to possible answers and explanations that merited scoring.

The review stage, involves students being assigned two peer submissions anonymously. The students were required to download and review the submissions based on the set criteria, in addition to making constructive comments for each review. As a motivation, students were awarded 5 marks for each completed review. The feedback stage marked the end of the peer assignment review process. Students received feedback from their two peers and grades awarded by the lecturers. If students were not satisfied with the feedback received then they would flag the review which would then be moderated by the lecturer. Students sent emails to the course mailing list in case they needed help with using the application.

\section{Data Collection}

During the second half of the semester, a survey questionnaire was delivered. The questionnaire aimed to capture student's experience and willingness to adopt the peer assignment review process in their learning activities. In addition, the questionnaire aimed to elicit the students' understanding of the potential pedagogical benefits. The validity of the questionnaire was based on two aspects: First, the questionnaire items used were contextually modified from adapted and modified from De Raadt et al.[12] and Wood \& Kurzel [13]. Secondly, the questionnaire was pre-tested on 10 randomly selected students in the DBMS class. The pre-test aimed to examine the general structure, clarity, and relevance of the questionnaire items. At completion of the pre-test, feedback received from the participants was used to modify the questionnaire.

\section{Data Analysis}

Data obtained from the survey was imported into SPSS for analysis. Ordinal logistic regression (OLR) was used to study the effect of independent variables on the dependent/outcome variable. Ferdousi \& Levy [14] affirms that OLR does not require the assumption of linearity in the relation between independent and dependent variables. It estimates the magnitude of the effect of the independent variables on the 
dependent variable, thus making it superior in predicting the likelihood of dependent variable using independent variables [15]. Ordinal logistic regression is used when developing models to predict ordinal variables [16].

In the study, the learning process was treated as the dependent/outcome variable which constituted of five items (Ques_5A, Ques_5B, Ques_5C, Ques_5D and Ques_5E). The independent variables constituted of 18 items (Ques_10A Ques 10D = 4 Items; Ques_11A - Ques_11F = 6 Items and Ques_12A - Ques_12H $=8$ Items). The dependent and independent variables were scored on a likert scale (1-Strongly Disagree, 2-Disagree, 3-Neutral, 4-Agree, 5-Strongly Agree). The ordinal regression model was fitted to each of the five dependent/outcome variables of the learning process and analysed separately in order to observe the effect of the various independent variables concerning peer assignment review process, The study had a different hypothesis for each of the dependent variables. The independent variables were categorical thus treated as factors.

The purpose of this study was to establish the perceived students change in the learning process as a result of the peer assignment review process. As a result the analysis focused on two aspects: Firstly, establishing if the models improve the ability to predict the outcome. Secondly, ascertaining which variables (independent variables) related to the peer assignment review process has a significant effect on the learning process items (dependent variable).

\section{RESULTS}

\section{A. Descriptive Results}

Out of the 998 students who were enrolled to the Database Management Systems course, 458 students voluntarily responded to the survey, of which 401 responses were usable. This accounted for $87.6 \%$ valid students responses with a gender composition of $42 \%$ female and $58 \%$ male distribution. $13.7 \%$ were registered BIS students, $36.4 \%$ were BIT students, $10.7 \%$ were BSE students and $39.2 \%$ were CSC students. The 18 questionnaire items related to the peer assignment review process were examined to ascertain the change in the participants learning process. The questionnaire items presented a high level of reliability with a Cronbach alpha coefficient of 0.912. George \& Mallery (2003) indicate that a Cronbach alpha coefficient $>.8$ provides a good measure of internal consistency of items in the scale.

\section{B. Examining the Change in the Learning Process}

Results indicate that variables that had a significant effect on the student learning process items in relation to the peer assignment review process at $95 \%$ level of confidence. This implies that the significant variables led to changes in the learning process with everything held at a constant. The model fitting statistics indicated that the observed data was consistent with the estimated values of the fitting models as follows, for Ques_5A $\left(\chi^{2}=189.856, \mathrm{df}=72\right.$ and sig $\left.=.000\right)$; Ques_5B $\left(\chi^{2}=\right.$ 137.365 , df $=72$ and $\operatorname{sig}=.000)$; Ques_5C $\left(\chi^{2}=151.096\right.$, df $=72$ and sig $=.000)$; Ques_5D $\left(\chi^{2}=168.814, \mathrm{df}=72\right.$ and sig $=$ $.000)$; Ques_5E $\left(\chi^{2}=207.990, \mathrm{df}=72\right.$ and sig $\left.=.000\right)$. The result indicates that the models are likely to predict the outcome since they are significant. In relation to the peer assignment review process variables and their effect on the learning process, parameter estimates for independent variables derived from each of the models were analysed (Table 1).

TABLE I. PARAMETER Estimates For VARIABLES RELATED TO THE PeEr Assignment Review Process On The LeARning Process

\begin{tabular}{|c|c|c|c|}
\hline \multicolumn{2}{|r|}{ Variables } & Estimates & Sig. \\
\hline \multicolumn{4}{|c|}{$\begin{array}{c}\text { Question 5A. The assignment inspired me to reflect on my use and } \\
\text { understanding of course concepts }\end{array}$} \\
\hline [Ques_12B=2] & $\begin{array}{l}\text { Peer assignment review process made } \\
\text { me more interested in the topic }\end{array}$ & -2.026 & .014 \\
\hline \multicolumn{4}{|c|}{$\begin{array}{c}\text { Question 5B. The assignment inspired me to search and learn beyond the } \\
\text { material provided to me in class }\end{array}$} \\
\hline [Ques_11F=3] & $\begin{array}{l}\text { Peer review feedback has added value } \\
\text { for students }\end{array}$ & -.797 & .027 \\
\hline [Ques_12C=3] & $\begin{array}{l}\text { Peer assignment review process } \\
\text { motivated me to improve my work }\end{array}$ & -1.579 & .002 \\
\hline \multicolumn{4}{|c|}{$\begin{array}{c}\text { Question 5C. I received enough support from other students to complete the } \\
\text { assignment (Group discussions) }\end{array}$} \\
\hline [Ques_10C=3] & $\begin{array}{l}\text { Seeing other students using the system } \\
\text { encouraged me to use it also }\end{array}$ & -1.029 & .013 \\
\hline [Ques_11A=4] & $\begin{array}{l}\text { I found the peer review process helped } \\
\text { me to better reflect on my own work }\end{array}$ & -.844 & .006 \\
\hline [Ques_11F=2] & $\begin{array}{l}\text { Peer review feedback has added value } \\
\text { for students }\end{array}$ & 1.783 & .017 \\
\hline [Ques_12D=1] & \begin{tabular}{|l|} 
I felt secure about using the peer \\
assignment review application
\end{tabular} & -3.020 & .007 \\
\hline [Ques_12G=1] & $\begin{array}{l}\text { I got assistance from fellow students } \\
\text { when I failed to use the peer review } \\
\text { system }\end{array}$ & -1.986 & .000 \\
\hline \multicolumn{4}{|c|}{$\begin{array}{c}\text { Question 5D. When I saw other students assignments I compared them to my } \\
\text { own assignment }\end{array}$} \\
\hline [Ques_10D=1] & $\begin{array}{l}\text { Completing reviews anonymously } \\
\text { allowed me to give feedback without } \\
\text { bias }\end{array}$ & -2.525 & .008 \\
\hline [Ques_11A=3] & $\begin{array}{l}\text { I found the peer review process helped } \\
\text { me to better reflect on my own work }\end{array}$ & -1.637 & .005 \\
\hline [Ques_11C=3] & $\begin{array}{l}\text { I was able to improve on my quality } \\
\text { of assignment as a result of } \\
\text { participating in the peer review } \\
\text { process }\end{array}$ & -1.221 & .008 \\
\hline [Ques_11D=3] & $\begin{array}{l}\text { Feedback about my assignment came } \\
\text { quickly from my peers than from the } \\
\text { lecturer }\end{array}$ & -1.142 & .005 \\
\hline [Ques_12E=4] & $\begin{array}{l}\text { I liked reviewing other students } \\
\text { assignments }\end{array}$ & .863 & .012 \\
\hline [Ques_12G=3] & $\begin{array}{l}\text { I got assistance from fellow students } \\
\text { when I failed to use the peer review } \\
\text { system }\end{array}$ & -1.691 & .001 \\
\hline [Ques_12H=1] & $\begin{array}{l}\text { I would be happy to use the same } \\
\text { submission and review system in } \\
\text { other courses }\end{array}$ & -1.804 & .005 \\
\hline \multicolumn{4}{|c|}{$\begin{array}{l}\text { Question } 5 E \text {. Through completing the reviews of other students work I } \\
\text { developed a better understanding of the concepts covered in the assignment and } \\
\text { the course }\end{array}$} \\
\hline [Ques_10B=2] & $\begin{array}{l}\text { Communicating with other students } \\
\text { through reviewing their assignments } \\
\text { gave me the sense of belonging to the } \\
\text { class }\end{array}$ & -1.954 & 028 \\
\hline [Ques_11E=2] & $\begin{array}{l}\text { Peer review allows for effective } \\
\text { sharing and development of } \\
\text { knowledge and information }\end{array}$ & -2.313 & 023 \\
\hline [Ques_12F=1] & $\begin{array}{l}\text { I was confident in carrying out the } \\
\text { peer assignment review }\end{array}$ & -4.141 & 015 \\
\hline
\end{tabular}

- Ques_5A. The assignment inspired me to reflect on my use and understanding of course concepts 
Results indicate that Ques_12B=2 (peer assignment review process made students more interested in the topic) has a significant negative effect (Estimate $=-2.026, \mathrm{p}<.05$ ) on Ques_5A (The assignment inspired me to reflect on my use and understanding of course concepts). This implies that for the participants who strongly agreed that the assignment inspired me to reflect on my use and understanding of course concepts, tended to strongly disagree that the peer assignment review process made students more interested in the topic.

- Ques_5B. The assignment inspired me to search and learn beyond the material provided to me in class

The OLR analysis indicate that Ques_11F=3 (peer review feedback has added value for students) and Ques_12C=3 (the peer assignment review process motivates students to improve my work) have a significant negative effect (Estimate $=-.797$, $\mathrm{p}<.05)$ and (Estimate $=-1.579, \mathrm{p}<.05)$ respectively on Ques_5B (the assignment inspired me to search and learn beyond the material provided to me in class). The result indicate that participants who strongly agreed that the assignment inspired them to search and learn beyond the material provided to me in class, tended to strongly disagree that peer review feedback has added value for students and that the peer assignment review process motivates students to improve my work.

- Ques_5C. I received enough support from other students to complete the assignment

From the OLR analysis, it was established that Ques_10C=3 (seeing other students using the system encouraged students to use it also), Ques_11A=4 (I found the peer review process helped students to better reflect on my own work), Ques_12D=1 (I felt secure about using the peer assignment) and Ques_12G=1(I got assistance from fellow students when I failed to use the peer review system) have a significant negative effect (Estimate $=-1.029, \mathrm{p}<.05$ ), $($ Estimate $=-.844, \mathrm{p}<.05), \quad($ Estimate $=-3.020, \quad \mathrm{p}<.05)$, (Estimate $=-1.986, \mathrm{p}<.05)$ respectively on Ques_5C (I received enough support from other students to complete the assignment), while Ques_11F=2 (peer review feedback has added value for students) has a positive significant effect (Estimate $=1.783, \mathrm{p}<.05)$. These results indicate that participants who strongly agreed that they received enough support from other students to complete the assignment, tended to strongly disagree that seeing other students using the system encouraged students to use it also, the peer review process helped students to better reflect on my own work, they felt secure about using the peer assignment and that they got assistance from fellow students when I failed to use the peer review system. In addition results also imply that participants who strongly agreed that they received enough support from other students to complete the assignment, tended to strongly agree that peer review feedback has added value for students.

- Ques_5D. When I saw other students assignments I compared them to my own assignment

Results derived from the analysis in Table 1 indicated that Ques_10D=1 (Completing reviews anonymously allowed me to give feedback without bias); Ques_11A=3 (I found the peer review process helped me to better reflect on my own work), Ques_11C=3 (I was able to improve on my quality of assignment as a result of participating in the peer review process), Ques_11D=4 (Feedback about my assignment came quickly from my peers than from the lecturer), Ques_12G=3 (I got assistance from fellow students when I failed to use the peer review system) and Ques_12H=1 (I would be happy to use the same submission and review system in other courses) have a significant negative effect (Estimate $=-2.525, \mathrm{p}<.05$ ), $($ Estimate $=-1.637, \mathrm{p}<.05), \quad($ Estimate $=-1.221, \mathrm{p}<.05)$, $($ Estimate $=-1.142, \mathrm{p}<.05),($ Estimate $=-1.691, \mathrm{p}<.05)$ and (Estimate $=-1.804, \mathrm{p}<.05)$ respectively on Ques 5D (When I saw other students assignments I compared them to my own assignment), while Ques_12E=4 (I liked reviewing other students assignments) had a positive significant effect (Estimate $=.863, \mathrm{p}<.05)$. These results indicate that participants who strongly agreed that when I saw other students assignments I compared them to my own assignment tended to strongly disagree that completing reviews anonymously allowed me to give feedback without bias, they were able to improve on my quality of assignment as a result of participating in the peer review process, feedback about my assignment came quickly from my peers than from the lecturer, they got assistance from fellow students when they failed to use the peer review system and happy to use the same submission and review system in other courses. Results also implied that participants who strongly agreed that when saw other students assignments they compared them to their own assignment also strongly agreed that they liked reviewing other students assignments.

- Question 5E. Through completing the reviews of other students work I developed a better understanding of the concepts covered in the assignment and the course

OLR analysis results presented in Table 1, showed that Ques_10B=2 (Communicating with other students through reviewing their assignments gave me the sense of belonging to the class), Ques_11E=2 (Peer review allows for effective sharing and development of knowledge and information) and Ques_12F=1 (I was confident in carrying out the peer assignment review) have a significant negative effect with $($ Estimate $=-1.954, \mathrm{p}<.05),($ Estimate $=-2.313, \mathrm{p}<.05)$ and (Estimate $=-4.141, \mathrm{p}<.05)$ respectively on Ques_5E (Through completing the reviews of other students work I developed a better understanding of the concepts covered in the assignment and the course). This implies that participants who strongly agreed that through completing the reviews of other students work I developed a better understanding of the concepts covered in the assignment and the course tended to strongly disagree that communicating with other students through reviewing their assignments gave them the sense of belonging to the class, that the peer review allows for effective sharing and development of knowledge and information and that they were confident in carrying out the peer assignment review.

\section{DISCUSSION}

The study reported in this paper aimed at studying the relationship between various variables related to peer assignment review process and their effect on the perceived change in the student learning process. It was envisaged that students would learn from each other and look at different perspectives presented by peers in order to improve the quality 
of their work and enhance their understanding of the course concepts [2] as such supporting their learning process. The results derived from the study indicate that the effect of the peer assignment review process on the students learning process was limited, as a result accounting to the insignificant perceived change in the students learning process.

Results indicated that although the assignment inspired students to reflect on the use and understanding of the course concepts, the peer assignment review process did not make then interested in the topic. This can be attributed to the fact that peer assignment review process was not aligned with the course objectives, thus affecting the learning outcome and students' expectations. Biggs [17] refers to the term "constructive alignment" whereby the desired learning outcomes are communicated to students, and learning activities and assessment tasks are coordinated to achieve these outcomes. Worth noting is that the peer assignment review process was a new concept that the students and lecturers were not used to and constructive alignment between the learning outcomes, assessment evidence and learning experiences was lacking.

In addition, results show that the assignment inspired students to search and learn beyond the material provided in class, and the peer review feedback did not have added value for the students. It was observed that although the feedback received from the students was timely in some cases it was unsatisfactory. $97 \%$ of the student assignments were moderated by the lecturers, based on the fact that the students were not satisfied with the reviews they received from their peers. Studies such as Sharpe \& Benfield [18] and Ramsey [19] on collaborative and peer learning observed that it is difficult to engage students beyond interaction and information-sharing to constructive peer reviews. It was further noted that the peer assignment review process did not motivate students to improve their work. The educational culture of the research context and in most developing countries is lecturer-centred with lecturers as providers of information and students as receivers of information. In an effort to leapfrog students into the new collaborative e-learning dimension, there is a need for lecturer scaffolding to support and drive the learning process. The lecturer assumes a facilitator role encouraging focused learning and facilitating constructive interactions and reviews during the learning process.

As reported in Cassidy [20] students expressed concern regarding their ability and that of others to carry out the reviews. Willey \& Gardner [21] view feedback as arguably the most important part because of its potential to affect future learning and student achievement. If feedback is not focused correctly (to inspire and motivate students to learn rather than circumvent their reflection and thinking) it may encourage dependent rather than independent learning. Fordyce \& Mulcahey [22] established that students do not naturally take to the role of critic, attributing it to students shying away from commenting on their peers, their fear of alienating fellow students or their lack of the critical skills necessary to carry out the reviews. This point to the need to empower students and create opportunities among students to practice reviews in order to develop the required peer review skills. Walker [23] reports a change in students' attitude towards a positive perception of the peer review process resulting from these opportunities. Increasing students' familiarity with the peer review process and improving their skills can alleviate the perceived difficult sense of responsibility among them [20]. This implies that the introduction of the peer assignment review process should be gradually implemented to allow for effective and sustainable change in the learning process. From a technology acceptance perspective it can be inferred that a person using a technology or an application should find it free of effort [24]. In some instances technology and online environments can be frustrating, pointing to the lack of technology skills among the students [25], affecting the level of student involvement in the peer assignment review process. Zhu et al. [26] assert that computer competence is a significant predictor of students' achievement in online courses.

The findings indicate that effective sharing and development of knowledge and information through the peer assignment review process had a negative significant effect on the students' learning process. This finding contradicts findings reported in Richardson, et al. [9] that the peer review can foster an authentic learning environment in which students actively construct knowledge through reading, questioning ideas and reflecting on their own and peers' work. Wilson [27] adds that developing shared understanding among students is achieved through group consensus on knowledge, communicating and discussing different ideas and receiving feedback. As a result students learn by explaining their ideas to peers while participating in the process of inquiry. It is through this process that cognitive functions such as critical thinking increase, thus facilitating the learning process [9].

Developing a community provides motivation for learning, encourages engagement and reduces isolation [28]. Students interact to construct meaningful and worthwhile knowledge, an aspect that is crucial in any learning environment [29]. This confirms previous claims that student interaction can be related to deep learning, critical thinking, higher cognitive development and long-term knowledge retention [30]. It was observed that the pedagogical culture in the research context did not support such collaborative/interactive engagements, probably because the sense of community and connectedness resulting from the interaction in the peer assignment review process was not significant in providing a sense of belonging among students. The results indicated, however, that participants liked reviewing other students' work and comparing it with their own. This result may be related to the fact that students were curious to ascertain how other students had performed in the assignment. This creates competition among students which can lead to improved learning [31]. In addition, Pare \& Joordens [32] affirm that reviewing peers' work encourages deep analysis of students' own work, resulting in improved quality of work.

\section{CONCLUSION}

This paper presents and discusses the application of a peer assignment review process for collaborative e-learning to learning activities of DBMS course taken by third year students at Makerere University. The aim was to determine the effect of peer assignment review process on the student learning process. The four peer assignment review process stages; 
familiarization, assignment, review and feedback [11] were applied to the students learning activities during their semester period. Recent studied have claimed that the peer review process supports the learning process [1, 9]. However the results of this study indicate that peer assignment review process is a new concept yet to be comprehended and thus had limited impact on the students learning. This can be attributed to several factors limiting effective adoption and use of the peer assignment review process.

It was observed that while students were aware of the benefits and challenges derived from adopting and using the peer assignment review process; they were also reluctant to fully embrace as an approach to support their learning process. This can be attributed to the fact that students were not familiar to the learning approach which was implemented in a short time and they lacked the maturity to use the collaborative elearning approach. Another possible explanation could be that student's expectation with regards to the peer assignment review process was based on their experience in the traditional learning environment. From a behaviourism perspective, learning is an observable change in behaviour that can be achieved by applying the concept of drill and practice [33]. In a sense students are accustomed to a certain form of learning after practicing it for a period of time and hence adapt to change. It should be noted that the students were not fully prepared for the peer assignment review process. An implication for further studies can be gradual implementation of the peer assignment review process to allow for effective and sustainable changes in the learning process.

Furthermore, students lacked the skills to review and critique their peers assignment. Indeed, Fordyce \& Mulcahey [22] assert that students do not naturally take to the role of critic, attributing it students shying away from commenting on their peers, fear of alienating fellow students or that they do not have the critical skills necessary to carry out the reviews. However it is worth noting that continual engagement of students in the peer assignment review process can develop the review skills resulting into constructive feedback. The study observed that the varying levels of ICT literacy impacted on the adoption and use of the peer assignment review process. While some students were quick to submit and carryout the reviews others were struggling, thus sought help on using the system. This points to the relevance of ICT skills development in the study context to facilitate effective adoption and use of collaborative e-learning [34] to support the learning process.

Managing change is another factor that was apparent in the study context to have negatively impacted on students when using the peer assignment review process as part of their learning activity. Using student to pedagogically support each other's learning process through the peer assignment review process, puts students at the centre of the learning process. However this study has observed that it is difficult to engage students beyond interaction and information sharing to constructive peer reviews. This can be attributed to the traditional learning environment students are used to and the students expectations for lecturers involvements and provision of guidance. The educational culture in most developing countries is lecturer-centered with lecturers as providers of information and students as receivers of information. In an effort to leapfrog students into the new collaborative e-learning dimension, there is need for lecturer scaffolding to support and drive the learning process. The lecturer assumes a facilitator role encouraging focused learning and facilitating constructive interactions and reviews during the learning process.

\section{ACKNOWLEDGMENT}

Special thanks to Prof. Gebrenegus Ghilagaber, Dr. E.S.K Muwanga-Zake, Asrat Temesgen and J.B Asiimwe for helping with the data analysis.

\section{REFERENCES}

[1] E. Eryilmaz, N. Alrushiedat, and J. Van der Pol. The Effect of Anchoring Online Discussion on Collaboration and Cognitive Load. in The Fifteenth Americas Conference on Information Systems. 2009. San Francisco, California.

[2] L. Chung-Hsien, S. Graf, K.R. Lai, and Kinshuk, Enrichment of Peer Assessment with Agent Negotiation. IEEE Transactions on Learning Technologies, 2011, vol 4, no.1, pp. 35-46.

[3] H.J. So and T.A. Brush, Student perceptions of collaborative learning, social presence and satisfaction in a blended learning environment: Relationships and critical factors. Computers \& Education, 2008. vol.51, pp. 318-336.

[4] L. Vygotsky, Mind in Society: The development of Higher psychological process, Cambridge: Havard University Press, 1978.

[5] J. Piaget, The Psychology of Intelligence, New York: Harcourt and Brace, 1950.

[6] S. Turner, M.A. Pérez-Quiñones, and J. Chase, Exploring Peer Review in the Computer Science Classroom. Computing Research Repository., 2009.

[7] K.J. Topping, E.F. Smith, I. Swanson, and A. Elliot, Formative Peer Assessment of Academic Writing between Postgraduate Students. Assessment \& Evaluation in Higher Education, 2000, vol 25, no.2, pp. 149-69.

[8] S. Sahin, An Application of Peer Assessment in Higher Education. The Turkish Online Journal of Educational Technology, 2008, vol 7, no.2, pp. 5-10.

[9] J.C. Richardson, P.A. Ertmer, J.D. Lehman, and T.J. Newby. Using peer feedback in online discussions to improve critical thinking. in Proceedings of the Annual Meeting of the Association for Educational Communications and Technology,Anaheim, CA, 2007.

[10] C.H. Lan, S. Graf, K.R. Lai, and Kinshuk, Enrichment of Peer Assessment with Agent Negotiation. IEEE Transaction on Learning Technologies, 201, vol 4, no.1, pp. 35-46.

[11] K.E. Kahiigi, M. Vesisenaho, H. Hansson, M. Danielson, and F.F. Tusubira, Modelling a Peer Assignment Review Process for Collaborative E-learning. Journal of Interactive Online Learning, 2012, vol.11, no.2, pp. 67-79.

[12] M. De Raadt, M. Toleman, and R. Watson. Electronic peer review: A large cohort teaching themselves. in In Proceedings of the 22nd Annual Conference of the Australasian Society for Computers in Learning in Tertiary Education (ASCILITE’05), Brisbane, QUT, Brisbane, 2009.

[13] D. Wood and F. Kurzel. Engaging students in reflective practice through a process of formative peer review and peer assessment. in ATN Assessment Conference 2008: Engaging Students in Assessment. Adelaide, 2008.

[14] B. Ferdousi and Y. Levy, Development and Validation of a Model to Investigate the Impact of Individual Factors on Instructors' Intention to Use E-learning Systems. Interdisciplinary Journal of E-Learning and Learning Objects, 2010, vol.6.

[15] B.J. Ferdousi, A Study of Factors that Affect Instructors' Intention to Use E-Learning Systems in Two-Year Colleges, in Graduate School of Computer and Information Sciences,Nova Southeastern University, 2009.

[16] J.P. Hoffmann, Generalized linear models: An applied approach, Boston, MA: Pearson Education Inc, 2004. 
[17] J.B. Biggs, Teaching for quality learning at universityBuckingham, UK: Open University Press, 1999.

[18] R. Sharpe and G. Benfield, The Student Experience of E-learning in Higher Education: A Review of the Literature. Brookes eJournal of Learning and Teaching, 2005, vol.1, no.3.

[19] C. Ramsey, Using Virtual Learning Environments to Facilitate New Learning Relationships. International Journal of Management Education, 2003, vol. 3, no.2, pp. 31-41.

[20] S. Cassidy, Developing employability skills: peer assessment in higher education. Education + Training, 2006, vol.48, no.7, pp. 508-517.

[21] K. Willey and A. Gardner, Investigating the capacity of self and peer assessment activities to engage students and promote learning. European Journal of Engineering Education, 2010, vol. 35, no.4, pp. 429-443.

[22] B. Fordyce and S. Mulcahey. Overcoming obstacles to student collaboration in peer review of written work Collaboration and Active Learningm Available from: http://iutconference.com/model.pdf, 2012

[23] A. Walker, British psychology students perception of group work and peer assessment. Psychology Learning and Teaching, 2001, vol. 1, no.1, pp. 28-36.

[24] F.D. Davis, R.P. Bagozzi, and P.R. Warshaw, User acceptance of computer technology: A comparison of two theoretical models. Management Science, 1989, vol. 35, no.8, pp. 982-1003.

[25] V. Cantoni, M. Cellario, and M. Porta, Perspectives and challenges in elearning: towards natural interaction paradigms. Journal of Visual Languages \& Computing, 2004, vol. 15,no.5, pp. 333-345.

[26] C. Zhu, M. Valcke, T. Schellens, and Y. Li, Chinese Students' Perceptions of a Collaborative E-Learning Environment and Factors Affecting Their Performance: Implementing a Flemish E-Learning Course in a Chinese Educational Context. Asia Pacific Education Review, 2009, vol. 10, no.2, pp. 225-235.

[27] G. Wilson, Online interaction impacts on learning: Teaching the teachers to teach. Australasian Journal of educational Technology, 2004, vol. 20, no. 1 , pp. 33-48.

[28] C. Gray and K. Smyth, Collaboration Creation: Lessons Learned From Establishing an Online Professional Learning Community. The Electronic Journal of e-Learning Volume Issue, 2012, vol. 10, no.1, pp. 60-75.

[29] D.R. Garrison, Online community of inquiry review: Social, cognitive and teaching presence issues. Journal of Asynchronous Learning Networks, 2007, vol. 11, no.1, pp. 61-72.

[30] B. De Wever, T. Schellens, M. Valcke, and H. Van Keer, Content analysis schemes to analyze transcripts of online asynchronous discussion groups: A review. Computers \& Education, 2006, vol. 46, pp. 6-28.

[31] R. Takaoka, M. Shimokawa, and T. Okamoto, A Development of GameBased Learning Environment to Activate Interaction among Learners. IEICE TRANSACTIONS on Information and Systems, 2012. vol. E95D, no.4, pp. 911-920.

[32] D.E. Pare and S. Joordens, Peering into large lectures: examining peer and expert mark agreement using peerScholar, an online peer assessment tool. Journal of Computer Assisted Learning, 2008, vol. 24, no.6, pp. 526-540.

[33] F. Mödritscher, E-Learning Theories in Practice: A Comparison of three Methods. Journal of Universal Science and Technology of Learning, 2006, vol. 0, no.0, pp. 3-18.

[34] K.E. Kahiigi, H. Hansson, M. Danielson, F.F. Tusubira, and M. Vesisenaho. Collaborative E-learning in a Developing Country: A University Case Study in Uganda. in 10th European Conference on eLearning ECEL-2011, Brighton Business School, University of Brighton, UK, 2011.

\section{AUTHORS PROFILE}

Evelyn Kigozi Kahiigi holds a Masters degree in Computer Science and is currently pursuing a $\mathrm{PhD}$ in Computer and Systems Sciences at Department of Computer and Systems Sciences, Stockholm University, Sweden. Her particular research interest is in collaborative e-learning, with specific focus on how it can be adopted and used effectively in a developing country context.

Mikko Vesisenaho is a research coordinator at the Human Technology Unit, Agora Center at the University of Jyväskylä, Finland. Dr. Vesisenaho's multidisciplinary educational and academic background is from education and computer science. He has several years experience of working on East African ICT education research projects.

Dr. F. F. Tusubira is the current CEO of UbuntuNet Alliance for Research and Education Networking. He is actively involved in ICT policy and regulation formulation.

Henrik Hansson is Associate Professor and head of research in IT and learning at the Department of Computer and Systems Sciences, Stockholm University, Sweden. He is interested in the technology and learning

Mats Danielson is Professor in Computer and Systems Sciences at Stockholm University, Sweden. He is also the Vice Dean of the Social Science department. He is interested in computers in society, including decision support and analysis. 